\title{
Caracterização Tecnológica da Madeira de Acacia mangium Willd em Plantio Consorciado com Eucalipto
}

\author{
Fabricio Gomes Gonçalves ${ }^{1}$, Roberto Carlos Costa Lelis ${ }^{2}$ \\ ${ }^{1}$ Departamento de Ciências Florestais e da Madeira, Universidade Federal do Espírito Santo - UFES \\ ${ }^{2}$ Departamento de Produtos Florestais, Universidade Federal Rural do Rio de Janeiro - UFRRJ
}

\begin{abstract}
RESUMO
A espécie Acacia mangium apresenta potencial silvicultural no país, em função da sua boa adaptação e do seu rápido crescimento. É muito utilizada em recuperação de áreas antropizadas, porém ainda pouco estudada no que se refere às propriedades tecnológicas de sua madeira, sobretudo em árvores mais jovens. Dessa forma, o objetivo deste trabalho foi avaliar a densidade básica, o teor de extrativos, o valor do $\mathrm{pH}$ e a capacidade tampão da madeira de Acacia mangium, além de descrevê-la anatomicamente. Foram utilizadas árvores com 4,2 anos, provenientes de reflorestamento misto com o híbrido Eucalyptus urophylla $\times$ grandis, localizado no município de Santa Bárbara, região do Vale do Rio Doce, Estado de Minas Gerais. Análises químicas, físicas e anatômicas na madeira obtida em diferentes alturas do tronco foram realizadas. A densidade básica média encontrada foi de $0,34 \mathrm{~g} \cdot \mathrm{cm}^{-3}$. A madeira não apresentou uma grande acidez e os valores de pH e capacidade tampão da madeira variaram de 5,45 a 5,90 e de 0,05 a $0,104 \mathrm{mmolNaOH}$, respectivamente. Os extrativos encontrados apresentaram baixos teores, indicando não haver uma variação significativa ao longo da árvore. Os caracteres anatômicos apresentaram comportamento com pequenas variações quando comparados com árvores mais adultas.
\end{abstract}

Palavras-chave: tecnologia da madeira, qualidade da madeira, madeira juvenil.

\section{Technological Characterization of Wood from Acacia mangium Willd Grown in Mixed Plantations with Eucalypt}

\begin{abstract}
Acacia mangium species presents silvicultural potential in the country due to its good adaptability and fast growth. It is widely used in renovation of disturbed areas; however, there are few studies on the technological properties of its wood, especially in younger trees. Thus, the purpose of this research was to evaluate the density, extractives content, $\mathrm{pH}$ value and buffer capacity of the Acacia mangium wood, as well as to describe it anatomically. 4.2-year-old trees were used; they were planted in reforestation mixed with the Eucalyptus urophylla $\times$ grandis hybrid, located in Santa Barbara, State of Minas Gerais. Chemical, physical and anatomical analyses of the wood at different stem heights were carried out. The results showed an average wood basic density of $0.34 \mathrm{~g} . \mathrm{cm}^{-3}$. The wood did not show high acidity; the $\mathrm{pH}$ and buffer capacity ranged from 5.45 to 5.90 and from 0.05 to $0.104 \mathrm{mmolNaOH}$, respectively. The extractives found presented low levels, indicating no significant variation along the tree. The anatomical characters presented small variations in behavior when compared to older trees.
\end{abstract}

Keywords: wood technology, wood quality, juvenile wood. 


\section{INTRODUÇÃO}

A utilização, sobretudo a econômica e a sustentável das florestas, notadamente aquelas de crescimento rápido, é muito estudada. Um exemplo típico de aproveitamento de espécies de rápido crescimento é o de Eucalyptus spp. A madeira de eucalipto desempenha um papel de grande relevância no setor florestal do país. Segundo a Associação Brasileira de Produtores de Florestas Plantadas, existem atualmente 4,51 milhões de hectares florestados com esse gênero (ABRAF, 2010). A maioria dos estudos relativos à madeira de espécies de rápido crescimento é realizada com base em povoamentos puros. Quando associadas a plantios mistos, pouco ainda se sabe das alterações das características da madeira que podem ocorrer quando de seu desenvolvimento.

A espécie Acacia mangium Wild. é uma leguminosa pioneira e muito cultivada em todo o mundo, especialmente para energia primária (Vale et al., 2000) e celulose (Alencar, 2009). É pertencente à família Leguminosae, subfamília Mimosoideae, cujo gênero compreende aproximadamente 700 a 800 espécies (Lamprecht, 1990), habitando naturalmente áreas tropicais e subtropicais. Em razão da boa forma do fuste e das boas possibilidades de uso (serrado, energia e painéis), tem chamado a atenção de vários pesquisadores em diversas partes do mundo (Veiga et al., 2000). Recentemente, têm-se realizado estudos para utilização de sua madeira para produção de partículas destinadas à indústria de compósitos de madeira, puros ou através de mix com outras espécies de menor densidade (Silva, 2008).

A espécie se destaca por possuir um crescimento relativamente rápido (Veiga et al., 2000) e um bom desenvolvimento em várias regiões do país, não sendo exigente em solos (Falesi, 2006); é imprópria para regiões com geadas fortes e déficits hídricos (Antunes, 2009), apresentando madeira de baixa densidade $\left(0,52\right.$ g.cm $\left.{ }^{-3}\right)$ (Vale et al., 1999).

O conhecimento das propriedades tecnológicas de uma madeira é de fundamental importância para se conhecer a sua qualidade e o direcionamento de seu uso (Hillig, 2000). As propriedades da madeira interferem em vários processos de sua utilização. Com relação às propriedades químicas, a presença de extrativos se destaca com grande efeito no uso de uma madeira, podendo comprometer a eficiência de processos de colagem (Rowell et al., 2005). Os extrativos são um grupo de substâncias químicas presentes na parede celular e são constituídos basicamente de gorduras, fenóis, terpenos, esteroides, ácidos diversos, breu, ceras e muitas outras combinações orgânicas; tais combinações ou até mesmo essas substâncias isoladas são responsáveis por conferir cor, cheiro e durabilidade à madeira.

Com relação às propriedades tecnológicas da madeira de Acacia mangium, alguns trabalhos já foram realizados. Antunes (2009) destaca algumas características dessa madeira: anéis de crescimento indistintos, cerne claro e alburno distinto, elementos de vasos dispostos em padrão não específico com diâmetro tangencial de 120 a $160 \mu \mathrm{m}$, sem presença de tilos nos vasos, sendo a frequência destes de 4 a 9 por $\mathrm{mm}^{2}$.

O objetivo principal do presente trabalho é caracterizar tecnologicamente a madeira da espécie Acacia mangium de 4,2 anos, obtida em plantios de forma consorciada com o híbrido Eucalyptus urophylla $\times$ grandis.

\section{MATERIAL E MÉTODOS}

\subsection{Descrição do material e da região de coleta de material}

O estudo foi realizado a partir de dez árvores iniciais de Acacia mangium com 4,2 anos (50,4 meses) de idade, escolhidas ao acaso, porém com diâmetros entre 9 e $15 \mathrm{~cm}$, em uma área experimental cultivada em consórcio com o híbrido Eucalyptus urophylla $\times$ grandis, pertencentes à empresa CENIBRA S.A., localizada no município de Santa Bárbara-MG. Após o abate e a obtenção dos discos, foram escolhidas apenas cinco árvores para o estudo, com exceção para a densidade básica, tendo em vista algumas árvores apresentarem a parte central do tronco desprovida de madeira. As demais foram transformadas em partículas para posterior confecção de painel aglomerado.

O plantio está situado na microrregião Itabira, com clima tropical de altitude, inverno seco e verão brando e úmido. Possui temperatura mínima de 
$17,1^{\circ} \mathrm{C}$ e máxima de $26,7^{\circ} \mathrm{C}$, sendo os meses de julho e fevereiro os mais frios e quentes, respectivamente. A precipitação anual está em torno de $1.440 \mathrm{~mm}$.

\subsection{Metodologia}

\subsubsection{Avaliação das características físicas e químicas da madeira}

\subsubsection{Densidade básica}

A partir das dez árvores, foram obtidas seções transversais (discos) de $2,5 \mathrm{~cm}$ de espessura, ao longo do tronco nas posições $0 \%$ (base), 25\%, 50\%, $75 \%$ e $100 \%$ (topo), além de um disco extra à altura do DAP (1,30 m do solo). A partir desses discos, retirou-se uma cunha em $25 \%$ destes, da qual se obteve a densidade básica da madeira mediante o método de imersão em água, conforme descrito por Vital (1984). Buscou-se também uma regressão matemática para estimar a densidade em função da altura do tronco, aplicando-se teste de student na significância dos coeficientes a $1 \%$.

O restante dos discos foi utilizado para determinação do teor de extrativos, do pH (água quente e fria) e da capacidade tampão, além de estudos anatômicos nos planos radial, tangencial e axial.

\subsubsection{Teor de extrativos}

Os discos, de um total de cinco, foram transformados em cavacos, com posterior trituração em um moinho de facas tipo Willey. A serragem obtida foi peneirada para homogeneidade do material, utilizando-se aquelas que ficaram retidas na malha de número 16 (malha 40 ASTM). Os extrativos foram obtidos conforme descrito por Abreu et al. (2006), mediante uma amostra de madeira (15 g) absolutamente seca, para cada posição (item 2.2.1.1).

As partículas de madeira foram transferidas para um extrator soxhlet, seguindo uma escala eluitrópica de ordem crescente de polaridade dos seguintes solventes: ciclohexano (1:2), acetato de etila e metanol, por 24 horas para cada solvente e, em seguida, concentrado em um rotavapor.

O teor de extrativos foi obtido a partir da diferença entre a massa inicial seca antes e depois de passar pelo processo de extração, considerando-se a quantidade de partículas (base seca) empregada na extração, em porcentagem.

\subsubsection{Valor do pH e capacidade tampão da madeira}

$\mathrm{O}$ pH e a capacidade tampão foram determinados mediante solubilização de $5 \mathrm{~g}$ de partículas (base seca) da madeira em $150 \mathrm{ml}$ de água destilada, sob refluxo $\left(100^{\circ} \mathrm{C}\right)$ por 20 minutos e à temperatura ambiente $\left(23^{\circ} \mathrm{C}\right)$ por 24 horas.

Foram pipetados em um Becker, após calibração do pH-metro digital com soluções tampão 4 e 7, $50 \mathrm{ml}$ de extratos aquosos, sendo mantidos sob agitação por 5 minutos. $\mathrm{O} \mathrm{pH}$ inicial foi obtido e, posteriormente, os extratos foram titulados com solução de $\mathrm{NaOH} 0,001 \mathrm{~N}$ até $\mathrm{pH} 7$ para a determinação da capacidade tampão ácida em $\mathrm{mmol} / \mathrm{L}$, posteriormente transformados em mmolNaOH/5 g. Foram realizadas 12 repetições para cada árvore na condição ambiente $\left(20^{\circ} \mathrm{C}\right)$ e oito repetições por árvore na condição aquecida $\left(100^{\circ} \mathrm{C}\right)$.

\subsubsection{Descrição anatômica quantitativa}

Nos discos obtidos para cada posição, retirouse uma amostra na região do alburno no sentido axial da árvore. Essa decisão foi tomada em razão de algumas árvores estarem ocadas nas três primeiras posições do fuste, não permitindo, dessa forma, a obtenção da amostra no cerne.

Foram realizadas mensurações dos elementos anatômicos utilizando-se cortes histológicos e materiais dissociados. Para as fibras, foram feitos macerados de acordo com o método do peróxido de hidrogênio/ácido acético descrito por Ramalho (1987), sendo posteriormente mensurados em microscópio ótico comum, com auxílio de um sistema analisador de imagens. Para os vasos, foram realizados cortes anatômicos com auxílio de um micrótomo de deslize, com montagem temporária em glicerina destilada e água na proporção 1:1. As mensurações foram realizadas em um microscópio ótico comum e um analisador de imagens com software específico. Os estudos anatômicos seguiram os procedimentos preconizados pela norma (COPANT, 1974) e IAWA-Committee (IAWA, 1989). 


\subsubsection{Mensuração de vasos e raios}

Nas posições radial, tangencial e axial, foram cortados corpos de prova nas dimensões de $1 \times 1,5 \times 2 \mathrm{~cm}$, nas direções radial, tangencial e longitudinal, respectivamente. Estes foram fervidos com água destilada à ebulição e fixados em micrótomo de deslize para obtenção dos cortes de espessura variando de 18 a $20 \mu \mathrm{m}$ nos planos transversal e longitudinal tangencial, sendo em seguida montados em lâminas temporárias, com uso de glicerina e água.

Em relação aos vasos, foram feitas micrografias das lâminas anteriormente descritas, com a utilização de uma câmara fotográfica digital de 7.1 megapixels, adaptada ao microscópio ótico. As leituras e medições foram realizadas no analisador de imagem. Os parâmetros mensurados relativos aos vasos foram a frequência vascular em poros. $\mathrm{mm}^{-2} \mathrm{e}$ o diâmetro tangencial em micrômetro.

Para cada disco, foram realizadas 30 repetições para frequência e 30 para diâmetro tangencial dos vasos, em cada posição, totalizando, para cada árvore, 180 repetições. Em relação aos raios, com o mesmo sistema analisador de imagem, foram mensurados o comprimento e a largura, ambos em $\mu \mathrm{m}$, e também a frequência, em raios. $\mathrm{mm}^{-1}$.

Para os discos na altura do peito (DAP), foram confeccionadas lâminas permanentes, utilizando cortes histológicos dos planos, com um total de 30 repetições para frequência, comprimento e largura do raio.

\subsubsection{Mensuração das fibras}

Os corpos de prova, depois de obtidas as lâminas, foram transformados em cavacos e posteriormente submetidos ao processo de maceração. Os cavacos foram transferidos para um vidro de $25 \mathrm{ml}$ contendo uma solução de ácido acético e peróxido de hidrogênio (proporção 1:1), sendo lacrado e transferido para estufa $\left(60{ }^{\circ} \mathrm{C}, 48\right.$ horas), segundo método descrito por Ramalho (1987).

Esgotada a solução macerante após a secagem, a suspensão de células foi lavada em água destilada, corada em safranina e, posteriormente, foram montadas lâminas histológicas sobre água destilada e glicerina em proporção de 1:1. Depois de fotografadas, as imagens obtidas com uma câmara fotográfica digital de 7.1 megapixel acoplada a um microscópio ótico comum foram utilizadas para mensuração do comprimento, da largura e do diâmetro de lume, por meio do sistema analisador de imagens.

As macerações das fibras foram realizadas segundo os procedimentos da norma COPANT (1974), considerando-se 20 repetições por posição e totalizando 100 macerações para cada árvore. A espessura da parede foi obtida por meio da relação entre a diferença da largura e do diâmetro da fibra por dois, com valores expressos em micrômetros.

\subsection{Análise dos dados}

Após coleta dos dados, os mesmos foram dispostos em planilha eletrônica e analisados por meio de estatística simples, por meio da média, do desvio padrão e do coeficiente de variação, mediante apresentação em gráfico e Tabela para ilustração dos parâmetros estudados. Quando possível, aplicou-se análise de regressão, sempre a $5 \%$ de significância; isso foi necessário, uma vez que as árvores foram obtidas na mesma condição de manejo.

\section{RESULTADOS E DISCUSSÃO}

\subsection{Caracterização física e química da madeira}

As árvores apresentaram um diâmetro à altura do peito médio da ordem de $10,7 \mathrm{~cm}+/-1,14 \mathrm{~cm}$ com alturas totais médias de $14,90 \mathrm{~m}+/-1,57 \mathrm{~m}$. As árvores estudadas apresentaram uma densidade básica média da ordem de $0,34 \mathrm{~g} . \mathrm{cm}^{-3}$. A análise de variância apresentou diferença estatística a ( $p<0,001)$ para essa propriedade, indicando, dessa forma, haver diferenças no sentido axial da árvore.

O comportamento da densidade básica na direção base-topo das árvores de Acacia mearnsii é apresentado na Figura 1.

A densidade para a espécie segue a mesma tendência encontrada por Vale et al. (1999) para árvores com sete anos de idade. Conforme ilustrado na Figura 1, o componente quadrático, significativo, explica $66,6 \%$ da variação total, apresentando boa distribuição dos pontos em relação à curva. Destaca- 
se a densidade na porção da base como a maior $\left(0,45 \mathrm{~g} \cdot \mathrm{cm}^{-3}\right.$ em média), estatisticamente diferente das demais alturas $(\mathrm{p}<0,001)$ e um baixo coeficiente de variação $(10,82 \%)$.

A densidade básica apresentou uma diminuição ao longo do tronco até $75 \%$ da altura, com ligeiro acréscimo a partir desse ponto (Figura 1). Em função de as árvores estarem se desenvolvendo em consórcio com eucalipto, pode ter ocorrido um estiolamento do tronco associado a menores intensidades de ramos e nós, ou mesmo uma redução do lenho outonal, contribuindo para diminuição de possíveis alterações anatômicas nessas posições. A partir de $75 \%$ da altura, a presença mais efetiva de galhos e ramos contribuiu para obtenção de maiores valores de densidade.

A Tabela 1 apresenta os valores médios de $\mathrm{pH}$ e de capacidade tampão ácida para a madeira estudada em função da temperatura de obtenção.

Os valores de $\mathrm{pH}$ e tamponamento ácido para a madeira de Acacia mangium encontrados indicaram certa heterogeneidade entre as árvores pela análise de variância com significância a $5 \%$. Os valores

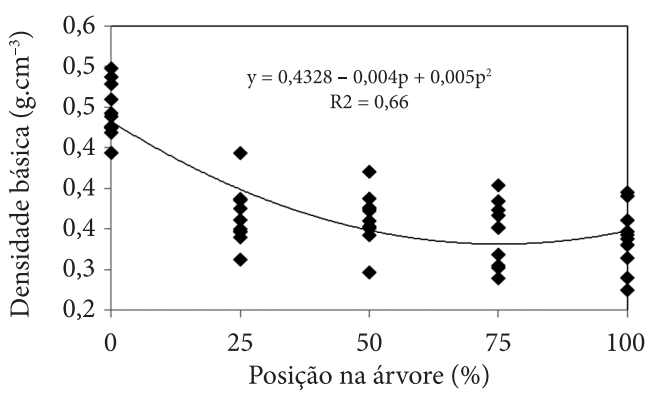

Figura 1. Variação da densidade básica da madeira nas porcentagens da altura do tronco para as árvores estudadas de Acacia mangium ( $\mathrm{p}=$ posição em $\mathrm{cm}$ ).

Figure 1. Variation of wood basic density in different percents of the height trees for Acacia mangium $(\mathrm{p}=$ position in $\mathrm{cm})$. de $\mathrm{pH}$ e tamponamento variaram de 5,45 a 5,90 e 0,05 a $0,104 \mathrm{mmolNaOH}$, respectivamente. De acordo com Albuquerque et al. (2005), madeiras com valores de $\mathrm{pH}$ mais ácidos são mais indicadas para colagem com resinas à base de ureia, já que esta também possui caráter levemente mais ácido se comparada com resinas à base de fenol. De acordo com Almeida (2009), a capacidade tampão da madeira mostra capacidade que a mesma apresenta para resistir à variação de $\mathrm{pH}$ do meio. A capacidade de tamponamento, assim como o valor $\mathrm{pH}$, variou em função da temperatura de solubilização das partículas em água. A madeira da acácia apresentou maior capacidade tampão ácida, quando solubilizada por 24 horas em água à temperatura ambiente, sob agitação.

Em estudo com a madeira de pinus e populus para confecção de um painel de fibras de média densidade $\left(0,74\right.$ g.cm $\left.{ }^{-3}\right)$, Xing et al. (2006) encontraram valores de capacidade tampão ácida na ordem de 0,0167 mmolNaOH para Populus spp. e de 0,0204 mmolNaOH para Pinus resinosa, valores esses bem inferiores ao do presente estudo. Possivelmente, a região climática e o sistema de cultivo das árvores podem ter influenciado neste comportamento.

Em trabalho com madeira de Schizolobium amazonicum, Colli (2007) encontrou valor médio de $\mathrm{pH}$ igual a 4,88, sendo bastante inferior ao encontrado neste trabalho para Acacia mangium. Almeida (2009) encontrou valores de $\mathrm{pH}$ para madeira de Pinus elliottii e Schizolobium amazonicum, respectivamente, para água fria e quente, 3,85 e 3,51, e 4,42 e 3,82. De acordo com a mesma autora, a solubilização da madeira em água quente por 20 minutos reflete de forma satisfatória o que ocorre durante a produção dos painéis. Isto é, quando, em um curto intervalo de tempo, a madeira recebe o adesivo e, em seguida, é prensada.

Tabela 1. Valores médios de $\mathrm{pH}$ e de capacidade tampão ácida para a madeira de Acacia mangium.

Table 1. Average values of $\mathrm{pH}$ and buffering acid capacity for the wood of Acacia mangium.

\begin{tabular}{lcc}
\hline Modo e tempo de extração & $\mathbf{p H}$ & $\begin{array}{c}\text { Capacidade tampão ácida } \\
(\mathbf{m m o l N a O H} / 5 \mathbf{g})\end{array}$ \\
\hline Água fria (ambiente) -24 horas & $5,662+/-0,233^{\mathrm{a}}$ & $0,088+/-0,020^{\mathrm{a}}$ \\
\hline Água quente -20 minutos & $5,572+/-0,212^{\mathrm{b}}$ & $0,066+/-0,023^{\mathrm{b}}$ \\
\hline
\end{tabular}

Médias seguidas pela mesma letra na coluna não diferem estatisticamente (Tukey, $p \geq 0,01$ ). 
Tabela 2. Média dos teores de extrativos obtidos da madeira de Acacia mangium em diferentes alturas do tronco com solventes ciclohexano (1:2), acetato de etila e metanol.

Table 2. Average content extract (\%) obtained from the wood of Acacia mangium along the trunk with solvent cyclohexane (1:2), ethyl acetate and methanol.

\begin{tabular}{|c|c|c|c|c|}
\hline \multirow{2}{*}{$\begin{array}{c}\text { Altura } \\
(\%)\end{array}$} & \multicolumn{3}{|c|}{ Solvente } & \multirow{2}{*}{ Total } \\
\hline & Ciclohexano & Acetato de etila & Metanol & \\
\hline 0 & $1,71 \pm 1,52$ & $0,40 \pm 0,18$ & $1,45 \pm 0,33$ & $1,19 \pm 1,02^{\mathrm{a}}$ \\
\hline 25 & $1,79 \pm 1,51$ & $0,32 \pm 0,07$ & $0,96 \pm 0,48$ & $1,02 \pm 1,05^{\mathrm{a}}$ \\
\hline 50 & $1,43 \pm 1,62$ & $0,27 \pm 0,06$ & $0,87 \pm 0,19$ & $0,85 \pm 1,00^{\mathrm{a}}$ \\
\hline 75 & $1,61 \pm 2,62$ & $0,31 \pm 0,15$ & $0,91 \pm 0,22$ & $0,94 \pm 1,57^{\mathrm{a}}$ \\
\hline 100 & $0,43 \pm 0,15$ & $0,31 \pm 0,15$ & $0,69 \pm 0,24$ & $0,49 \pm 0,24^{\mathrm{a}}$ \\
\hline Total & $1,39 \pm 1,61 \mathrm{a}$ & $0,33 \pm 0,31^{b}$ & $0,98 \pm 0,38^{a}$ & $0,89 \pm 1,45$ \\
\hline
\end{tabular}

${ }^{\star}$ Letras diferentes na coluna e na linha diferem estatisticamente (Tukey, $\mathrm{p} \geq 0,01$ ).

A Tabela 2 apresenta os teores médios de extrativos para a madeira de Acacia mangium utilizando os solventes ciclohexano (1:2), acetato de etila e metanol.

Observa-se uma tendência não significativa (Tukey, $\mathrm{p} \geq 0,01$ ) decrescente de redução dos extrativos totais presentes a partir da base em direção ao topo. É interessante mencionar que a própria cor dos extrativos obtidos apresentava-se diferente em função da altura, para um mesmo agente extrator, fato esse em função da polaridade dos mesmos quando em contato com os extrativos químicos presentes na madeira. No nível do DAP, a média dos extrativos ficou em $2,34 \% \pm 1,53$. Os extrativos presentes na madeira podem comprometer a eficiência de uma colagem na confecção de um painel, seja à base de partículas, seja em lâminas de madeira.

O ciclohexano proporcionou uma extração de maiores teores de extrativos, quando comparado com os demais extratores, indicando haver muitos elementos químicos apolares. Porém, era esperado haver maiores proporções com acetato de etila, em relação ao metanol, justamente em função da capacidade mais polar de extração do mesmo.

Gonçalves \& Lelis (2001), estudando cinco leguminosas arbóreas (idade entre 8 e 12 anos) - dentre as quais, a Acacia mangium - com DAP de $15 \mathrm{~cm}$, obtiveram, para o teor de extrativos, valores entre 5 e $8 \%$ para extração com água quente e com água e sulfito, respectivamente. O resultado foi 2,1 a 3,4 vezes superior ao encontrado neste estudo. Entretanto, deve-se considerar que a extração foi realizada com água e que as árvores avaliadas no presente trabalho apresentavam um
DAP inferior às árvores estudadas pelos autores citados; note-se, ainda, o fato de terem sido utilizadas árvores bem mais velhas. A água também foi utilizada por Lima et al. (2007) na determinação de extrativos presentes na madeira de candeia (Moquinia polymorpha), apresentando um total de $4 \%$, também superior ao verificado neste trabalho. A determinação de extrativos, também com água quente, permitiu uma extração de 9,14\% em madeira de sabiá (Mimosa caesalpiniaefolia), em trabalho realizado por Gonçalves et al. (2010).

Pan et al. (2007) realizaram uma retirada de parte dos extrativos em partículas de madeira de Eucalyptus saligna com água quente. Os resultados indicaram que a absorção de água teve uma redução de mais de 65\% e os módulos de ruptura e elasticidade apresentaram um acréscimo de 73,51\% e 85,05\%, respectivamente. Esse fato pode ser explicado pela reatividade de alguns componentes presentes na madeira que são prejudiciais no processo de colagem.

\subsection{Caracterização anatômica}

A Figura 2 apresenta a fotomicrografia para os planos transversal, radial e tangencial obtidos em corpo de prova à altura do peito, para a espécie Acacia mangium.

As dimensões das fibras (comprimento, largura, espessura e diâmetro do lume) e as informações relacionadas aos vasos e raios da madeira são importantes no contexto da formação de um painel aglomerado, uma vez que as propriedades físicas e mecânicas estão diretamente associadas a tais características. A Tabela 3 apresenta as características 

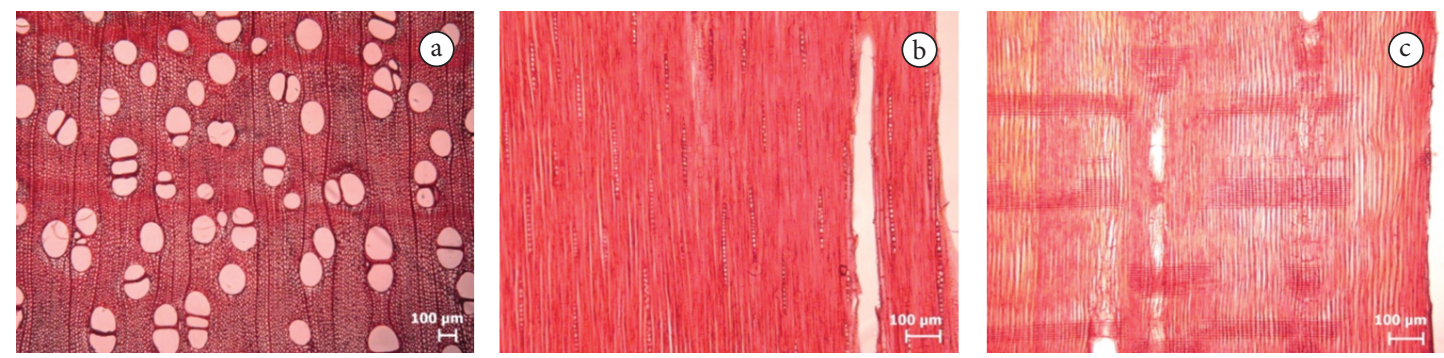

Figura 2. Fotomicrografias ilustrando os três planos observados para a estrutura anatômica da madeira de Acacia mangium: a) plano transversal, b) plano tangencial e c) plano radial na altura do DAP. Barra de escala $=100 \mu \mathrm{m}$. Figure 2. Photomicrographs illustrating the three levels observed for the anatomical structure of wood from Acacia mangium: a) transversal, b) tangential longitudinal, and c) radial longitudinal in DBH height. Scale bar $=100$ micrometers.

Tabela 3. Valores médios dos caracteres anatômicos avaliados na madeira de Acacia mangium em função da altura. Table 3. Average values of the anatomical characters evaluated in the wood of Acacia mangium along the trunk.

\begin{tabular}{|c|c|c|c|c|c|c|}
\hline \multirow{3}{*}{ Característica } & \multicolumn{5}{|c|}{ Posição no tronco (\%) } & \multirow{2}{*}{ Média } \\
\hline & $\mathbf{0}$ & 25 & 50 & 75 & 100 & \\
\hline & \multicolumn{6}{|c|}{ Fibra } \\
\hline Comprimento $(\mu \mathrm{m})$ & $946,68^{\text {a* }}$ & $809,74^{\mathrm{b}}$ & $801,43^{\text {bc }}$ & $749,34^{\text {cd }}$ & $700,81^{\mathrm{d}}$ & $802,20 \pm 179,87$ \\
\hline Largura total $(\mu \mathrm{m})$ & $26,59^{d}$ & $28,52^{\mathrm{cd}}$ & $29,14^{\mathrm{bc}}$ & $30,95^{\mathrm{ab}}$ & $31,55^{\mathrm{a}}$ & $29,35 \pm 6,25$ \\
\hline Largura do lume $(\mu \mathrm{m})$ & $17,23^{c}$ & $20,16^{\mathrm{b}}$ & $21,25^{\mathrm{b}}$ & $24,01^{\mathrm{a}}$ & $24,54^{\mathrm{a}}$ & $21,44 \pm 6,71$ \\
\hline Espessura da parede $(\mu \mathrm{m})$ & $4,68^{\mathrm{a}}$ & $4,18^{\mathrm{b}}$ & $3,95^{\mathrm{b}}$ & $3,47^{\mathrm{c}}$ & $3,51^{\mathrm{c}}$ & $3,96 \pm 1,07$ \\
\hline \multicolumn{7}{|l|}{ Vasos } \\
\hline Frequência (vasos/mm) & $9,23^{\mathrm{a}}$ & $6,25^{\mathrm{b}}$ & $5,35^{\mathrm{c}}$ & $4,55^{\mathrm{d}}$ & $5,12^{\text {cd }}$ & $6,09 \pm 2,87$ \\
\hline Diâmetro $(\mu \mathrm{m})$ & $126,12^{\mathrm{a}}$ & $118,63^{\mathrm{ab}}$ & $121,19^{\mathrm{a}}$ & $111,81^{\mathrm{bc}}$ & $105,37^{c}$ & $116,63 \pm 28,92$ \\
\hline \multicolumn{7}{|l|}{ Raios } \\
\hline Frequência (raios/mm) & $5,77^{\mathrm{a}}$ & $4,06^{\mathrm{c}}$ & $4,65^{\mathrm{b}}$ & $4,97^{\mathrm{b}}$ & $5,11^{\mathrm{b}}$ & $4,91 \pm 1,63$ \\
\hline Comprimento $(\mu \mathrm{m})$ & $153,55^{\mathrm{a}}$ & $159,89^{\mathrm{a}}$ & $137,06^{\mathrm{b}}$ & $119,98^{c}$ & $119,82^{c}$ & $138,06 \pm 53,94$ \\
\hline Largura $(\mu \mathrm{m})$ & $6,66^{\mathrm{a}}$ & $6,32^{\mathrm{ab}}$ & $5,94^{\mathrm{ab}}$ & $4,89^{c}$ & $5,35^{\mathrm{bc}}$ & $5,83 \pm 3,31$ \\
\hline
\end{tabular}

${ }^{*}$ Letras iguais na linha não diferem estatisticamente (Tukey, $\mathrm{p} \geq 0,01$ ).

anatômicas determinadas em função da altura das árvores.

As fibras encontradas para Acacia mangium são libriformes e muito curtas, com comprimento médio de 802,20 $\mu \mathrm{m}$, variando de 362,36 a 1.402,35 $\mu \mathrm{m}$. A largura (diâmetro do lume) variou entre 5,55 e $43,07 \mu \mathrm{m}$, com média de $21,44 \mu \mathrm{m}$, e a largura média total do lume encontrada foi de 29,35 $\mu \mathrm{m}$, variando de 13,61 a 48,20 $\mu \mathrm{m}$. As fibras apresentaram ainda paredes parcialmente delgadas, com espessura média da parede celular de 3,96 $\mu \mathrm{m}$, variando de 1,42 a $8,29 \mu \mathrm{m}$.

Os vasos são visíveis a olho nu, com parênquimas axiais praticamente imperceptíveis; quando presentes, são paratraqueais vasicêntricos, com distribuição difusa, predominantemente solitária a múltipla, sem tiloses, ovais a circulares. As placas de perfuração são simples. Os vasos são poucos frequentes, com uma frequência média de 6,09 vasos. $\mathrm{mm}^{-2}$, variando de 2 a 21 vasos. $\mathrm{mm}^{-2}$. Apresentam-se com diâmetros tangenciais médios, com tamanho médio de $116,63 \mu \mathrm{m}$, variando de 18,02 a $207,79 \mu \mathrm{m}$.

Os raios são homocelulares constituídos por células procumbentes, com estrutura não estratificada, e unisseriados. Apresentam-se muito finos, com largura média de 5,83 $\mu \mathrm{m}$, variando de 1,69 a $24,58 \mu \mathrm{m}$; são pouco frequentes, isto é, com uma frequência média de 4,91 raios/mm linear, variando de 1,00 a 11,00 raios/mm linear. Os raios são baixos, possuindo um comprimento médio (altura) de 138,06 $\mu \mathrm{m}$, variando de 40,71 $\mu \mathrm{m}$ a $390,03 \mu \mathrm{m}$.

A análise de variância (Tabela 4) apresentou diferenças em praticamente todos os caracteres anatômicos estudados entre as árvores em um nível 
Tabela 4. Resumo da Análise de Variância para as características anatômicas estudadas entre as árvores, para a madeira de Acacia mangium à altura do DAP.

Table 4. Summary of the analysis variance for anatomical characteristics studied among trees the wood from Acacia mangium in the DBH height.

\begin{tabular}{lccc}
\multicolumn{1}{c}{ Característica } & Coeficiente de variação (\%) & Quadrado médio & Significância (F) \\
\hline Comprimento da fibra $(\mu \mathrm{m})$ & 18,51 & 872075,1 & $<0,001$ \\
\hline Largura da fibra $(\mu \mathrm{m})$ & 20,23 & 394,26 & $<0,001$ \\
\hline Largura do lume $(\mu \mathrm{m})$ & 28,41 & 889,87 & $<0,001$ \\
Fração parede $(\%)$ & 31,05 & 2882,75 & $<0,001$ \\
Frequência de vaso $(\mathrm{vaso} / \mathrm{mm})$ & 38,43 & 516,75 & $<0,001$ \\
Diâmetro do vaso $(\mu \mathrm{m})$ & 24,06 & 9929,75 & $<0,001$ \\
Frequência do raio $(\mathrm{raio} / \mathrm{mm})$ & 31,20 & 59,08 & $<0,001$ \\
Comprimento do raio $(\mu \mathrm{m})$ & 37,26 & 51655,15 & $<0,001$ \\
\hline Largura do raio $(\mu \mathrm{m})$ & 55,76 & 77,31 & $<0,001$ \\
\hline
\end{tabular}

superior a 95\% de probabilidade, para a espécie Acacia mangium à altura do peito (DAP).

As fibras apresentaram comportamento dentro do esperado para a espécie, estando próximo daqueles encontrados por Antunes (2009). O autor avaliou árvores com seis anos de idade, contra 4,2 anos no presente trabalho, destacando-se a espessura da parede mais espessa no presente trabalho $(3,96 \mu \mathrm{m}$ contra $3,2 \mu \mathrm{m})$, provavelmente em função das condições de plantio misto com eucalipto, apesar da menor idade.

Conforme observado para as características dos vasos, por exemplo, uma frequência de vasos associados a elementos de dimensões elevadas poderá comprometer a colagem, por meio de uma linha de fuga mais intensa.

As características das fibras são controladas por fenômenos fisiológicos de ocorrência diferenciada para cada região (condição climática), o que pode variar de espécie para espécie (variação genética) e até dentro do mesmo indivíduo. Dessa forma, o comprimento das fibras é diretamente influenciado pelas divisões que ocorrem no câmbio (Panshin \& De Zeeuw, 1980). No presente estudo, em função da baixa idade e da condição silvicultural imposta à espécie, o comportamento anatômico pode ter sido comprometido, tornando as fibras com menores dimensões, se comparado aos trabalhos realizados por Antunes (2009). No entanto, para características como a espessura da parede, tal não foi observado, uma vez que foi encontrado um valor de 3,9 $\mu \mathrm{m}$ para a idade de 4,2 anos contra 3,2 $\mu \mathrm{m}$ para a idade de seis anos, em seu trabalho; desmistifica-se, assim, uma crença, pois nem todos os caracteres anatômicos são influenciados pela idade. Talvez possa ter acontecido o fato de a espécie ter se desenvolvido em sombreamento, comprometendo o desenvolvimento celular e causando um estiolamento dos elementos celulares, em comparação com a espécie cultivada na Indonésia em ambiente silvicultural homogêneo.

\section{CONCLUSÕES}

- A madeira de Acacia mangium apresentou baixa densidade básica, sendo o valor médio de $0,34 \mathrm{~g} \cdot \mathrm{cm}^{-3}$.

- A madeira não apresentou uma grande acidez. Os valores de $\mathrm{pH}$ e capacidade tampão da madeira variaram de 5,45 a 5,90 e de 0,05 a $0,104 \mathrm{mmolNaOH}$, respectivamente.

- A madeira apresentou baixos teores de extrativos, não havendo variação significativa ao longo da árvore.

- Os elementos anatômicos apresentaram-se sem variações significativas para a espécie, com exceção para os parênquimas axiais, os quais se encontram praticamente imperceptíveis por serem escassos nesse tecido.

- Tecnologicamente, a madeira apresenta características ideais para ser utilizada, por exemplo, na indústria de colagem de madeira, em razão dos baixos teores de extrativos e da acidez não elevada.

\section{AGRADECIMENTOS}

Os autores agradecem à Empresa Cenibra S/A pelo fornecimento da madeira da Acacia mangium. 


\section{STATUS DA SUBMISSÃO}

Recebido: $17 / 10 / 2011$

Aceito: 20/03/2012

Publicado: 30/09/2012

\section{AUTOR(ES) PARA CORRESPONDÊNCIA}

\section{Fabricio Gomes Gonçalves}

Departamento de Ciências Florestais e da Madeira - DEF, Universidade Federal do Espírito Santo - UFES, Rua Governador Lindemberg, 316, Centro, CEP 29550-000, Jerônimo Monteiro, ES, Brasil e-mail: fabricio.goncalves@ufes.br

\section{REFERENNCIAS}

Associação Brasileira de Produtores de Florestas Plantadas - ABRAF. Anuário Estatístico: ano base 2009. Brasília: ABRAF; 2010.

Abreu HS, Carvalho AM, Pereira RPW, Monteiro MBO, Silva HR, Souza KCA, et al. Métodos de análise em química da madeira. Floresta e Ambiente 2006, 20.

Albuquerque CEC, Iwakiri S, Keinert Junior S. Adesão e adesivos. In: Iwakiri S, editor. Painéis de madeira reconstituída. Curitiba: FUPEF; 2005.

Alencar GSB. Qualidade da madeira de espécies do gênero Acacia plantadas no Brasil [tese]. Piracicaba: Escola Superior de Agricultura Luiz de Queiroz, Universidade de São Paulo; 2009.

Almeida VC. Efeito da adição de carga e extensor nas propriedades do adesivo uréia-formaldeído e dos compensados de Pinus elliottii e Schizolobium amazonicum [dissertação]. Viçosa: Universidade Federal de Viçosa; 2009.

Antunes FS. Avaliação da qualidade da madeira das espécies Acacia crassicarpa, Acacia mangium, Eucalyptus nitens, Eucalyptus globulus e Populus tremuloides [dissertação]. Piracicaba: Escola Superior de Agricultura Luiz de Queiroz, Universidade de São Paulo; 2009.

Colli A. Caracterização da madeira de paricá (Schizolobium amazonicum Huber ex. Ducke) e propriedades de chapas de partículas aglomeradas com diferentes proporções de fibras de coco (Cocos nucifera L.) [dissertação]. Viçosa: Universidade Federal de Viçosa; 2007.

Comission Pan-Americana de Normas Técnicas - COPANT. Descripción de características generales, macroscópicas de las maderas angiopermas dicotiledóneas. COPANT; 1974. v. 30, p. 1-19.
Falesi IC. O Impacto da Acacia mangium no desenvolvimento sustentável do Estado do Pará [on line]. 2006. [cited 2010 dez. 8]. Available from: http:// www.scribd.com/doc/24820905.

Gonçalves CA, Lelis RCC. Teores de taninos da casca e da madeira de cinco leguminosas arbóreas. Floresta e Ambiente 2001; 8(1): 167-73.

Gonçalves CA, Lelis RCC, Abreu HS. Caracterização físico-química da madeira de sabiá (Mimosa caesalpiniaefolia Benth.). Revista Caatinga 2010; 23(1): 54-62.

Hillig E. Qualidade de chapas aglomeradas estruturais, fabricadas com madeiras de pinus, eucalipto e acácia negra, puras ou misturadas, coladas com taninoformaldeído [dissertação]. Santa Maria: Universidade Federal de Santa Maria; 2000.

International Association of Wood Anatomists Committee - IAWA. List of microscopic feature for hardwood identification. IAWA Bulletin 1989; 10(3): 220-332.

Lamprecht H. Silvicultura nos trópicos: Ecossistemas florestais e respectivas espécies arbóreas - Possibilidades e métodos de aproveitamento sustentado. Tradução de Guilherme de Almeida, Gilberto Calcagnotto. Eschborn: Dt. Ges. Für Techn. Zusammenarbeit (GTZ); 1990. 332 p.

Lima SR, Oliveira GS, Morais SAL, Nascimento EA, Chang R. Estudo dos constituintes macromoleculares, extrativos voláteis e compostos fenólicos da madeira de candeia - Moquinia polymorpha (LESS.) DC. Ciência Florestal 2007; 17(2): 145-155.

Pan Z, Zheng Y,Zhang R, Jenkins BM. Physical properties of thin particleboard made from saline eucalyptus. Industrial Crops and Products 2007; 26(2): 185-194. http://dx.doi.org/10.1016/j.indcrop.2007.03.006

Panshin AJ, De Zeeuw C. Text book of wood tecnology. New York: Mc Graw Hill; 1964.

Ramalho RS. O uso de macerado no estudo anatômico de madeiras. Viçosa: UFV; 1987.

Rowell RM, Pettersen R, Han JS, Rowell JS, Tshabalala MA. Cell wall chemistry. In: Rowell RM, editor. Handbook of wood chemistry and wood composites. Florida: CRC Press; 2005.

Silva FP. Reflorestamento de acácia: nova fonte de renda para o produtor florestal [on line]. 2008. [cited 2011 mai. 9]. Available from: http://www.remade.com.br/ br/revistadamadeira_materia.php?num $=1337 \&$ subjec $\mathrm{t}=$ Reflorestamento\&title $=$ Reflorestamento $\% 20 \mathrm{de} \% 20$ ac\%E1cia.

Vale AT, Brasil MAM, Carvalho CM, Veiga RAA. Produção de energia do fuste de Eucalyptus grandis Hill Ex-maiden e Acacia mangium Willd em diferentes níveis de adubação. Cerne 2000; 6(1): 83-88. 
Vale AT, Brasil MAM, Martins IS. Variação axial da densidade básica da madeira de Acacia mangium Willd aos sete anos de idade. Ciência Florestal 1999; 9(2): 85-92. Veiga RAA, Carvalho CM, Brasil MAM. Determinação de equações de volume para árvores de Acacia mangium. Cerne 2000; 6(1): 103-107.
Vital BR. Métodos de determinação da densidade da madeira. Viçosa: SIF; 1984.

Xing C, Zhang SY, Rield JDB, Cloutier A. Mediumdensity fiberboard performance as affected by wood fiber acidity, bulk density, and size distribution. Wood Science and Technology 2006; 40(8): 637-646. http:// dx.doi.org/10.1007/s00226-006-0076-7 